\title{
Erratum
}

\section{Erratum to: The Impact of Long Working Hours on Cognitive Function: A Follow-Up Study with Gender Stratification}

Pre-press 19 October 2021

Seunghyun Lee, Joon Yul Choi and Wanhyung Lee

[Journal of Alzheimer's Disease, 80(2) 2021, 727-734, DOI 10.3233/JAD-201404]

https://content.iospress.com/articles/journal-of-alzheimers-disease/jad201404

On page 729 , the wrong figure was printed as Figure 1. The correct figure is printed below.

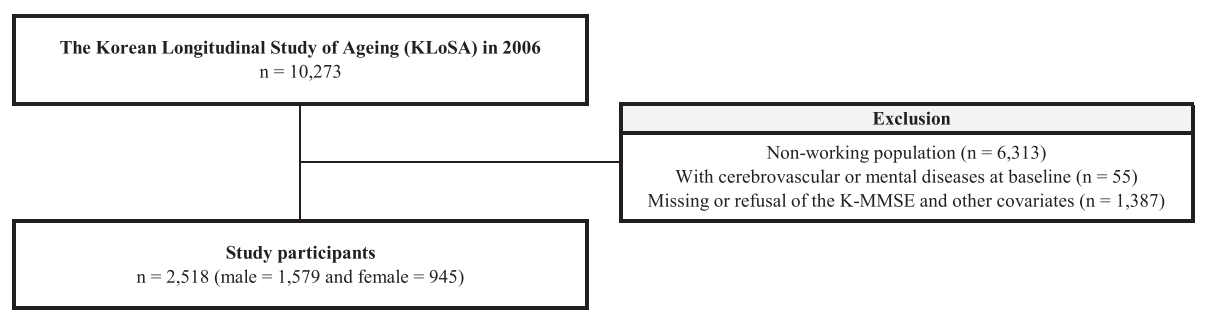

